\title{
PENDUGAAN JUMLAH PENDUDUK MISKIN DI INDONESIA PADA SUATU AREA KECIL DENGAN PENDEKATAN KERNEL-BOOTSTRAP
}

\author{
ELSA FEBRIANI, HAZMIRA YOZZA, IZZATI RAHMI HG \\ Program Studi S1 Matematika, \\ Fakultas Matematika dan Ilmu Pengetahuan Alam, Universitas Andalas, \\ Kampus UNAND Limau Manis Padang, Indonesia. \\ email : elsafebriani2002@gmail.com
}

\begin{abstract}
Abstrak. Kemiskinan diartikan sebagai suatu keadaan dimana taraf hidup manusia berada pada keadaan serba kekurangan dan tidak mampu untuk memenuhi kebutuhan dasar. Tingkat kemiskinan di Indonesia tergolong cukup tinggi, untuk mengurangi angka kemiskinan diperlukan beberapa upaya salah satunya pendugaan jumlah penduduk miskin di suatu daerah. Pendugaan yang dilakukan pada area kecil dapat dilakukan secara langsung dan secara tidak langsung. Pendugaan area kecil secara tidak langsung memanfaatkan informasi yang berhubungan dengan parameter yang diamati. Pendugaan tersebut dapat dilakukan dengan regresi parametrik dan regresi nonparametrik. Salah satu pendekatan yang dapat dilakukan pada regresi nonparametrik yaitu pendekatan Kernel. Metode pendekatan kernel lebih fleksibel dan memiliki kemampuan yang baik dalam memodelkan data yang tidak mempunyai pola tertentu. Evaluasi nilai pendugaan akan dilihat dengan nilai standar error. Pada regresi nonparametrik digunakan metode Bootstrap untuk memperoleh nilai standar error. Hasil pendugaan menggunakan regresi nonparametrik dengan pendekatan kernel menghasilkan nilai dugaan yang mendekati data sebenarnya dengan nilai standar error yang lebih kecil.
\end{abstract}

Kata Kunci: Small Area Estimation, Kernel, Bootstrap

\section{Pendahuluan}

Kemiskinan merupakan salah satu masalah perekonomian yang dihadapi oleh hampir setiap negara di dunia terutama negara berkembang seperti Indonesia. Tingkat kemiskinan di Indonesia masih tergolong cukup tinggi dikarenakan setiap tahunnya jumlah penduduk Indonesia terus meningkat.

Tingginya angka kemiskinan dipengaruhi oleh banyak faktor diantaranya laju pertumbuhan penduduk serta distribusi yang tidak merata, tingginya angka pengangguran yang diakibatkan oleh kurang tersedianya lapangan pekerjaan, rendahnya tingkat pendidikan, terjadinya bencana alam dan lain-lain. Kemiskinan juga dapat disebabkan oleh gagalnya program-program ekonomi yang direncanakan oleh pemerintah untuk menekan kemiskinan tersebut. 
Salah satu cara untuk mengukur kemiskinan di suatu daerah adalah dengan menentukan banyak penduduk miskin di daerah tersebut. Pendugaan jumlah penduduk miskin dapat dilakukan dengan dua cara yaitu pendugaan langsung (direct estimation) dan pendugaan tidak langsung (indirect estimation). Pendugaan secara langsung biasanya dilakukan pada area yang relatif besar. Apabila dilakukan pada area kecil, pendugaan tersebut tidak mampu memberikan ketelitian yang cukup sehingga statistik yang dihasilkan akan memiliki varian yang besar[6]. Oleh karena itu, apabila sampel diambil dari area kecil, perlu dikembangkan metode pendugaan tidak langsung yaitu pendugaan area kecil atau Small Area Estimation (SAE).

Teknik pendugaan dengan SAE merupakan teknik pendugaan secara tidak langsung dengan memanfaatkan informasi tambahan yang bersumber dari daerah itu sendiri ataupun daerah lain yang berhubungan dengan parameter yang akan diamati. Pendugaan secara tidak langsung dapat dilakukan dengan regresi parametrik dan regresi nonparametrik. Pendugaan secara tidak langsung dengan regresi nonparametrik salah satunya dapat dilakukan dengan pendekatan kernel karena lebih fleksibel dan memiliki kemampuan yang baik dalam memodelkan data yang tidak mempunyai pola tertentu.

\section{Landasan Teori}

\subsection{Analisis Regresi Linear Berganda}

Analisis regresi linear berganda digunakan untuk memodelkan hubungan secara linear antara dua atau lebih variabel bebas $\left(X_{1}, X_{2}, \cdots, X_{n}\right)$ dengan variabel terikat (Y). Bila terdapat $k$ variabel bebas yakni $X_{1}, \cdots, X_{k}$ maka model regresi yang digunakan adalah :[5]

$$
Y_{i}=\beta_{0}+\beta_{1} X_{i 1}+\beta_{2} X_{i 2}+\cdots+\beta_{k} X_{i k}+\varepsilon_{i},
$$

dengan : $Y_{i}$ adalah nilai pendugaan variabel terikat ke-i, $\beta_{0}, \beta_{1}, \cdots, \beta_{k}$ adalah parameter, $X_{i 1}, \cdots, X_{i k}$ adalah variabel bebas dan $\varepsilon_{i}$ adalah kesalahan/error.

Untuk mengestimasi parameter pada model analisis regresi linear berganda, salah satunya dapat menggunakan Metode Kuadrat Terkecil (MKT) yaitu dengan meminimumkan jumlah kuadrat residual $\left(\sum_{i=1}^{n} \varepsilon_{i}^{2}\right)$. Dengan MKT diperoleh nilai pendugaan $\beta$ yaitu

$$
\widehat{\beta}=\left(X^{T} X\right)^{-1}\left(X^{T} Y\right)
$$

\subsection{Regresi Nonparametrik}

Regresi nonparametrik digunakan untuk mengetahui pola hubungan antara variabel bebas dengan variabel terikat ketika tidak diperoleh informasi tentang bentuk fungsi regresinya. Pendekatan regresi nonparametrik bagi hubungan variabel bebas dan variabel terikat dimodelkan sebagai berikut :[3]

$$
Y_{i}=m\left(X_{i}\right)+\varepsilon_{i} ; i=1,2, \cdots, n,
$$

dengan $Y_{i}$ adalah variabel terikat pengamatan ke- $i, m\left(X_{i}\right)$ adalah fungsi pemulusan yang mendefenisikan hubungan antara penduga dengan variabel bebas pada pengamatan ke- $i$ dan $\varepsilon_{i}=$ error ke- $i$ dengan $\varepsilon_{i} \sim \mathrm{N}\left(0, \sigma^{2}\right)$. 


\subsubsection{Regresi Nonparametrik dengan Pendekatan Kernel}

Salah satu teknik yang dapat digunakan untuk mengestimasi regresi nonparametrik dengan pendekatan kernel adalah estimasi Nadaraya-Watson dimana fungsi regresi dinyatakan dengan

$$
\widehat{m}_{h}(x)=\frac{\sum_{i} K_{h}\left(x-X_{i}\right) Y_{i}}{\sum_{i} K_{h}\left(x-X_{i}\right)},
$$

dengan $K_{h}$ merupakan fungsi kernel dengan bandwidth (h).

Fungsi K(u) dikatakan fungsi kernel jika memenuhi sifat-sifat [8]

(1) $\mathrm{K}(-\mathrm{u})=\mathrm{K}(\mathrm{u})$, simetris.

(2) $\mathrm{K}(\mathrm{u}) \geq 0$, terbatas dan kontinu pada daerah asal $u$.

(3) $\int_{-\infty}^{\infty} K(u) d u=1$.

Fungsi kernel yang digunakan adalah fungsi kernel Epanechnikov.

$$
K(x)=\frac{3}{4}\left(1-x^{2}\right) I_{(|x| \leq 1)} .
$$

Bila terdapat lebih dari satu variabel bebas maka digunakan fungsi kernel multivariat. Bentuk dari fungsi kernel multivariat dapat dinyatakan dalam

$$
K_{h}\left(u_{1}, \cdots, u_{k}\right)=\prod_{j=1}^{k} \frac{1}{h} K\left(\frac{u_{j}}{h}\right)
$$

dengan $u_{j}=x_{j}-x_{i j}, i=1,2, \cdots, n$ dan $j=1,2, \cdots, k$.

\subsubsection{Bandwidth}

Lebar jendela atau bandwidth (h) merupakan parameter pemulusan (smoothing) yang berfungsi untuk menentukan kemulusan dari kurva yang dihasilkan. Pemilihan bandwidth yang optimal dilakukan dengan cara memperkecil tingkat kesalahan dimana semakin kecil tingkat kesalahan maka akan semakin baik estimasinya. [10]

Pemilihan bandwidth optimum pada penelitian ini dilakukan dengan meminimalkan Asymptotic Mean Integrated Square Error (AMISE) terhadap $h$. AMISE adalah persamaan yang dihasilkan dengan menghilangkan orde tertinggi dari pendekatan formula Mean Integrated Square Error (MISE). [1]

$$
\operatorname{AMISE}(\widehat{f}(x)) \approx \frac{h^{4}}{4}\left(\mu_{2}(K)\right)^{2} R\left(f^{\prime \prime}\right)+\frac{1}{n h} R(K)
$$

Jika Persamaan 2.7 diturunkan terhadap $h$ dan disamakan dengan 0 akan menghasilkan bandwidth optimal.

$$
h_{o p t}=(R(K))^{1 / 5} n^{-1 / 5}\left(\mu_{2}(K)\right)^{-2 / 5}\left(\frac{3}{8 \sqrt{\pi}}\right)^{-1 / 5} \sigma
$$




\subsection{Small Area Estimation (SAE)}

Small Area Estimation (SAE) atau pendugaan area kecil dapat dikatakan sebagai suatu metode untuk menduga parameter pada suatu area yang relatif kecil dalam percontohan survei dengan memanfaatkan informasi dari luar area, dari dalam area itu sendiri dan dari luar survei [7].

Penduga area kecil dibagi menjadi dua model yaitu model level area (basic area level model) dan model level unit (basic unit level model).

\subsubsection{Model Level Area}

Model level area merupakan model yang didasarkan pada ketersediaan variabel bebas yang hanya ada untuk level area tertentu. Misalkan $\mathbf{x}_{i}=\left(x_{1 i}, x_{2 i}, \cdots, x_{k i}\right)^{T}$ adalah variabel bebas dengan $\mathrm{i}$ adalah banyaknya area dan $\mathrm{k}$ adalah banyaknya variabel bebas serta parameter yang akan diduga adalah $\theta_{i}$ yang diasumsikan mempunyai keterkaitan dengan $\mathbf{x}_{i}[8]$. Variabel bebas tersebut digunakan untuk membangun model

$$
\theta_{i}=\mathbf{x}_{i}^{T} \beta+b_{i} v_{i}, i=1,2, \cdots, m
$$

dengan $b_{i}$ merupakan konstanta bernilai positif yang diketahui dan $\beta=$ $\left(\beta_{1}, \cdots, \beta_{k}\right)^{T}$ adalah vektor koefisien regresi berukuran $k \times 1$ dan $v_{i}$ adalah pengaruh acak dari area kecil yang diasumsikan dengan $v_{i} \sim \mathrm{N}\left(0, \sigma_{v}^{2}\right)$.

Untuk membuat kesimpulan mengenai area kecil $\theta_{i}$ pada Persamaan 2.9, diasumsikan bahwa pendugaan langsung $\widehat{\theta}_{i}$ diketahui yaitu

$$
\widehat{\theta_{i}}=\theta_{i}+e_{i}
$$

dengan kesalahan pengambilan sampel $e_{i} \sim \mathrm{N}\left(0, \sigma_{e}^{2}\right)$. Berdasarkan Persamaan 2.9 dan 2.10 didapatkan model gabungan :

$$
\widehat{\theta_{i}}=\mathbf{x}_{i}^{T} \beta+b_{i} v_{i}+e_{i}, i=1,2, \cdots, m
$$

dengan asumsi $v_{i}$ dan $e_{i}$ saling bebas. [9]

\subsection{SAE dengan Pendekatan Kernel}

Pendugaan pada suatu area kecil dapat dilakukan secara tidak langsung, salah satunya menggunakan regresi nonparametrik dengan pendekatan kernel. Dengan $\theta$ sebagai parameter yang akan diduga, maka pendugaan dari rataan area kecil tersebut dapat diperoleh dengan rumus : [6]

$$
\widehat{\theta}_{i}=\widehat{\gamma}_{i} Y_{i}+\left(1-\widehat{\gamma}_{i}\right) \widehat{m}_{h}\left(x_{i}\right)
$$

dimana $\widehat{\theta}_{i}$ merupakan penduga parameter yang akan diestimasi, $\widehat{\gamma}_{i}=\frac{\widehat{\sigma}_{u}^{2}}{\widehat{\sigma}_{u}^{2}+D_{i}}$ dengan $\widehat{\sigma}_{u}^{2}$ merupakan penduga varian antar area dan $D_{i}$ merupakan varian tiap area.

Nilai $D_{i}$ dapat dihitung dengan rumus :

$$
D_{i}=\frac{s_{i}^{2}}{n_{i}} \text { dengan } s_{i}^{2}=\frac{1}{n_{i}-1} \sum_{j=1}^{n_{i}}\left(Y_{i j}-Y_{i}\right)^{2}
$$


dengan $s_{i}^{2}$ merupakan varian, $n_{i}$ merupakan banyaknya jumlah area yang diamati pada area ke- $i, Y_{i j}$ merupakan variabel terikat ke- $j$ pada area ke- $i, Y_{i}$ merupakan variabel terikat pada area ke- $i$.

Untuk menghitung nilai dugaan dari varian antar area digunakan rumus :

$$
\widehat{\sigma}_{u}^{2}=\max \left\{0, \frac{1}{n-1} \sum_{i=1}^{m} W_{h i}(x)\left[Y_{i}-\widehat{m}_{h}\left(x_{i}\right)\right]^{2}-D\right\}
$$

\subsection{Pendugaan Standard Error (SE) dengan Bootstrap}

Metode bootstrap adalah metode berbasis resampling data sampel dengan syarat pengembalian dari sampel hasil observasi dengan replikasi B kali. Metode bootstrap merupakan suatu metode pendekatan nonparametrik untuk menaksir berbagai kuantitas statistik seperti mean, standar error, dan bias suatu estimator atau untuk membentuk selang kepercayaan dengan memanfaatkan kecanggihan teknologi komputer [4]. Nilai pendugaan standard error $\widehat{s e}_{B}$ dapat dihitung dengan

$$
\bar{\theta}^{*}=\frac{\sum_{i=1}^{B} \bar{\theta}_{i}^{*}}{B} \text { dan } \widehat{s e}_{B}=\left[\frac{\sum_{i=1}^{B}\left(\widehat{\theta}_{i}^{*}-\bar{\theta}^{*}\right)^{2}}{B-1}\right]^{1 / 2}
$$

\section{Pembahasan}

Hubungan antara variabel terikat dan variabel bebas dapat dilihat menggunakan diagram pencar berikut
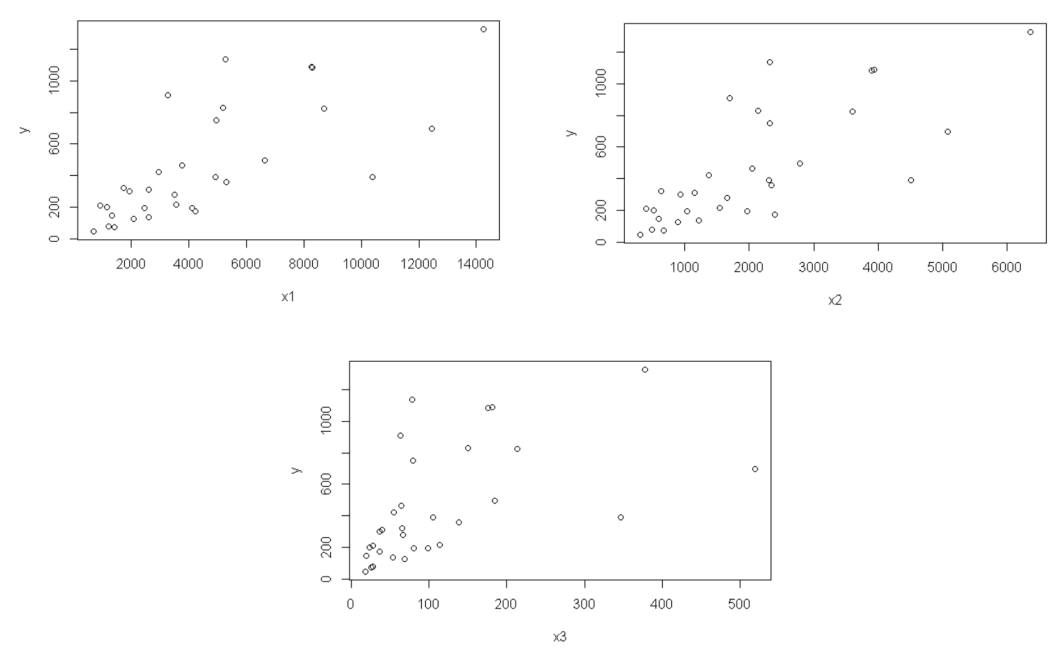

Gambar 1. Hubungan antara Variabel Terikat $(Y)$ dengan Variabel Bebas $\left(X_{1}, X_{2}, X_{3}\right)$

Berdasarkan Gambar 1 dapat dilihat bahwa hubungan antara variabel terikat dengan variabel bebas menggambarkan hubungan yang cendrung positif. 
44 Elsa Febriani, dkk

\subsection{Pendugaan Jumlah Penduduk Miskin dengan Analisis Regresi Linear Berganda}

Model yang terbentuk pada regresi parametrik yaitu

$$
\widehat{y}=-27,889+0,162 X_{i 1}+0,016 X_{i 2}-2,385 X_{i 3}
$$

Dengan menggunakan Persamaan 3.1 diperoleh hasil dugaan sebagai berikut

Tabel 1. Hasil Pendugaan Jumlah Penduduk Miskin

\begin{tabular}{|c|l|c|}
\hline NO & Provinsi & $\widehat{Y}$ (ribu) \\
\hline 1 & Aceh & 488,644 \\
2 & Sumatera Utara & 1484,595 \\
3 & Sumatera Barat & 540,907 \\
4 & Riau & 655,002 \\
5 & Jambi & 408,710 \\
6 & Sumatera Selatan & 942,439 \\
7 & Bengkulu & 213,870 \\
8 & Lampung & 956,993 \\
9 & Kepulauan Bangka Belitung & 151,717 \\
10 & Kepulauan Riau & 158,913 \\
11 & DKI Jakarta & 897,414 \\
12 & Jawa Barat & 3695,992 \\
13 & Jawa Tengah & 3831,785 \\
14 & DI Yogyakarta & 461,753 \\
15 & Jawa Timur & 4659,352 \\
16 & Banten & 830,800 \\
17 & Bali & 612,216 \\
18 & NTB & 622,500 \\
19 & NTT & 678,438 \\
20 & Kalimantan Barat & 557,457 \\
21 & Kalimantan Tengah & 285,034 \\
22 & Kalimantan Selatan & 435,111 \\
23 & Kalimantan Timur & 303,397 \\
24 & Kalimantan Utara & 45,387 \\
25 & Sulawesi Utara & 195,494 \\
26 & Sulawesi Tengah & 344,969 \\
27 & Sulawesi Selatan & 927,856 \\
28 & Sulawesi Tenggara & 317,755 \\
29 & Gorontalo & 113,820 \\
30 & Sulawesi Barat & 150,164 \\
31 & Maluku & 108,247 \\
32 & Maluku Utara & 110,211 \\
33 & Papua Barat & 60,181 \\
34 & Papua & 376,167 \\
\hline
\end{tabular}

Pendugaan jumlah penduduk miskin dengan regresi parametrik menghasilkan nilai standar error sebesar 234,610 .

\subsection{Small Area Estimation menggunakan Regresi Nonparametrik dengan Pendekatan Kernel}

Langkah pertama untuk menduga jumlah penduduk miskin di Indonesia dengan pendekatan kernel adalah dengan menduga nilai $\widehat{m}_{h}(x)$ dimana nilai bandwidth optimum $\left(h_{\text {opt }}\right)$ yang digunakan sebesar 200,385. Nilai bandwidth mempengaruhi 
tingkat kemulusan dari kurva. Semakin besar nilai bandwidth maka kurva pemulusan yang diperoleh semakin mulus namun dengan bias pendugaan semakin besar dan nilai ragam semakin kecil dan sebaliknya.

Setelah diperoleh nilai fungsi pemulusan, dapat diduga jumlah penduduk miskin untuk masing-masing provinsi $\left(\widehat{\theta}_{i}\right)$. Nilai fungsi pemulusan dan hasil pendugaan untuk masing-masing provinsi dapat dilihat pada Tabel 2

Tabel 2. Nilai $\widehat{m}_{h}(x)$ dan $\widehat{\theta}_{i}$ dalam (juta jiwa)

\begin{tabular}{|c|l|c|c|}
\hline NO & Provinsi & $\widehat{m}_{h}(x)$ & $\widehat{\theta}_{i}$ \\
\hline 1 & Aceh & 0,7705 & 0,829674 \\
2 & Sumatera Utara & 0,7768 & 1,324473 \\
3 & Sumatera Barat & 0,7707 & 0,360189 \\
4 & Riau & 0,7715 & 0,496773 \\
5 & Jambi & 0,7695 & 0,278844 \\
6 & Sumatera Selatan & 0,7727 & 1,085236 \\
7 & Bengkulu & 0,7684 & 0,302904 \\
8 & Lampung & 0,7727 & 1,081259 \\
9 & Kepulauan Bangka Belitung & 0,7680 & 0,076236 \\
10 & Kepulauan Riau & 0,7685 & 0,128530 \\
11 & DKI Jakarta & 0,7741 & 0,393747 \\
12 & Jawa Barat & 0,8005 & 3,666738 \\
13 & Jawa Tengah & 0,7912 & 4,078175 \\
14 & DI Yogyakarta & 0,7697 & 0,467105 \\
15 & Jawa Timur & 0,7950 & 4,276633 \\
16 & Banten & 0,7754 & 0,700135 \\
17 & Bali & 0,7701 & 0,176617 \\
18 & NTB & 0,7704 & 0,748301 \\
19 & NTT & 0,7706 & 1,133233 \\
20 & Kalimantan Barat & 0,7704 & 0,389094 \\
21 & Kalimantan Tengah & 0,7688 & 0,137941 \\
22 & Kalimantan Selatan & 0,7699 & 0,194676 \\
23 & Kalimantan Timur & 0,7695 & 0,218846 \\
24 & Kalimantan Utara & 0,7675 & 0,048581 \\
25 & Sulawesi Utara & 0,7697 \\
26 & Sulawesi Tengah & 0,194953 \\
27 & Sulawesi Selatan & 0,763599 \\
28 & Sulawesi Tenggara & 0,7678 & 0,7625862 \\
29 & Gorontalo & 0,313343 \\
30 & Sulawesi Barat & 0,201146 \\
31 & Maluku & 0,149617 \\
33 & Maluku Utara & Papua Barat & \\
34 & Papua & 0,320703 \\
& & 0,78311 \\
\hline
\end{tabular}

Nilai standar error untuk regresi nonparametrik dengan pendekatan kernel dihitung menggunakan metode bootstrap dengan banyak replikasi 50 kali. Replikasi ini dilakukan terhadap data asli sehingga diperoleh nilai standar error sebesar 0,0126. 


\section{Kesimpulan}

Berdasarkan hasil analisis dan pembahasan, dapat disimpulkan bahwa pendugaan jumlah penduduk miskin di Indonesia dengan metode regresi parametrik menghasilkan nilai dugaan dengan selisih cukup besar dari data sebenarnya. Sedangkan hasil pendugaan menggunakan metode regresi nonparametrik dengan pendekatan kernel lebih mendekati data sebenarnya. Hasil tersebut juga didukung oleh nilai error yang diperoleh.

\section{Daftar Pustaka}

[1] Aulia, A. 2015. Regresi Polinomial Lokal dengan Fungsi Kernel Gaussian. Skripsi, tidak diterbitkan. Universitas Gajah Mada. Yogyakarta

[2] Efron, B. dan R.J. Tibshirani. 1993. An Introduction to the Bootstrap. Chapman and Hall, New York

[3] Hardle, W. 1994. Applied Nonparametric Regression. Berlin

[4] Kurnia A, dan Notodipuro KA.2006.Penerapan Metode Bootstrap dalam Pendugaan Area Kecil. Jurnal Statistika dan Komputasi. 11: 12 - 16

[5] Kutner, M.H., Cristopher J. Nachtsheim, John Neter dan William Li. 2005. Applied Linear Statistical Models Edisi ke-5. McGraw-Hill, New York

[6] Maulana, U., Moh Yamin Darsyah dan Tiani Wahyu Utami. 2014. Small Area Estimation untuk Pendugaan Jumlah Penduduk Miskin di Kota Semarang dengan Pendekatan kernel-Bootstrap. Jurnal Statistika. 2: 63 - 69

[7] Mukhopadhyay P. dan Tapabrata Maiti. 2004.Two Stage Non-Parametric Approach for Small Area Estimation. Proceedings of ASA Section on Survey Research Methods: 4058 - 4065

[8] Niashinta, B.R., Dwi Ispriyanti dan Abdul Hoyyi. 2016. Pendugaan Area Kecil Terhadap Pengeluaran Per Kapita di Kabupaten Sragen dengan Pendekatan Kernel. Jurnal Gaussian. 5: 71 - 80

[9] Rao, J.N.K. 2003. Small Area Estimation. Wiley, London

[10] Silverman, B.W. 1986. Density Estimation for Statistics and Data Analysis. Chapman and Hall, New York 